\title{
Eight-year-old boy presenting with abdominal distention after blunt trauma in Liberia
}

\author{
Alexandra M Vinograd, ${ }_{1}^{1}$ Ansumana F Camara, ${ }^{2}$ Solomane A Konneh, ${ }^{2}$ \\ Patricia C Henwood ${ }^{3}$
}

${ }^{1}$ Department of Pediatrics, The Children's Hospital of Philadelphia, Philadelphia, Pennsylvania, USA

${ }^{2}$ Department of Surgery, Liberian College of Physician and Surgeons, Monrovia, Liberia

${ }^{3}$ Department of Emergency Medicine, Brigham and Women's Hospital, Boston, Massachusetts, USA

\section{Correspondence to} Dr Patricia C Henwood, phenwood@bwh.harvard.edu

Accepted 26 February 2016

\section{DESCRIPTION}

An 8-year-old boy presented with abdominal distension 1 week after a wall collapsed on him. Immediately after the injury, he developed abdominal distension. He was treated at an outside hospital and observed overnight. No imaging was available and he was discharged home the following day. His abdominal distension recurred the next day. He presented to another outside hospital and was referred to our institution.

Examination was remarkable for abdominal tenderness and distention with neither guarding nor rebound. Ultrasound showed free peritoneal fluid. The differential diagnosis included uroperitoneum, haemoperitoneum, faecal contents due to viscous injury and ascites unrelated to trauma. A bladder catheter was placed and drained $2500 \mathrm{~mL}$ of yellow fluid. Repeat ultrasound showed decreased ascites and the appearance of the catheter outside the bladder (figure 1), supporting the diagnosis of an intraperitoneal bladder rupture.

Intraoperatively, a bladder laceration was identified and repaired (figure 2). The catheter was maintained for 19 days. The patient was discharged home after successful voiding trials. The bladder is an intra-abdominal organ in children and at higher risk for injury than in adults, where it is protected by the pelvis. ${ }^{1}$ Intraperitoneal bladder ruptures occur when a blunt force to the abdomen causes increased intravesicular pressure and bladder dome rupture. $^{2}$ Static or CT cystograms are indicated when lower genitourinary trauma is suspected. ${ }^{2}$ These are often unavailable in limited-resource settings. Case reports exist documenting recognition of bladder rupture on ultrasound. ${ }^{3}$ Although ultrasound is neither as sensitive nor as specific a test, it may play an important role in evaluating such patients in limited-resource settings.

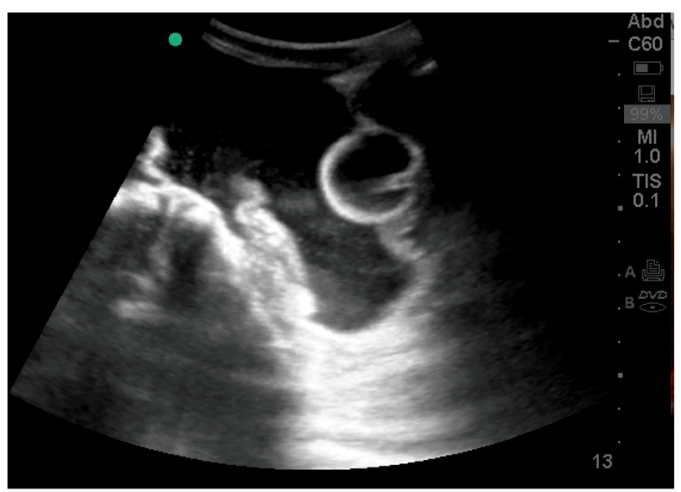

Figure 1 Ultrasound image demonstrating the bladder catheter outside the bladder wall.

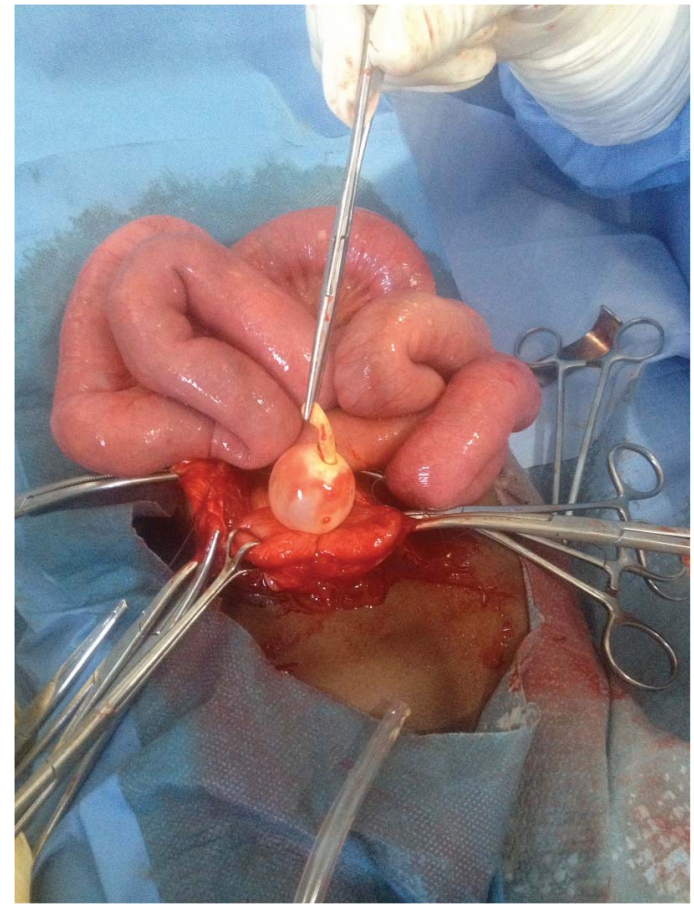

Figure 2 Intraoperative image of intraperitoneal bladder rupture with the catheter outside of the bladder wall.

\section{Learning points}

- Genitourinary injury should be considered in the setting of blunt trauma.

- Static or CT cystograms are indicated when lower genitourinary trauma is suspected.

- Ultrasound may play an important role in genitourinary trauma evaluation if other tests are not available.

\section{Twitter Follow Patricia Henwood at @PURE_Updates}

Contributors AMV, AFC and PCH had the idea for the article. AMV, AFC and SAK performed the literature search. All authors have contributed in writing and editing the article. $\mathrm{PCH}$ is the guarantor.

Competing interests None declared.

Patient consent Obtained.

Provenance and peer review Not commissioned; externally peer reviewed. 


\section{REFERENCES}

1 Osman Y, El-Tabey N, Mohsen T, et al. Nonoperative treatment of isolated posttraumatic intraperitoneal bladder rupture in children-is it justified? J Urol 2005;173:955-7.
2 Gomez RG, Ceballos L, Coburn M, et al. Consensus statement on bladder injuries. BJU Int 2004;94:27-32.

3 Wu TS, Pearson TC, Meiners $S$, et al. Bedside ultrasound diagnosis of a traumatic bladder rupture. J Emerg Med 2011;41:520-3.

Copyright 2016 BMJ Publishing Group. All rights reserved. For permission to reuse any of this content visit

http://group.bmj.com/group/rights-licensing/permissions.

BMJ Case Report Fellows may re-use this article for personal use and teaching without any further permission.

Become a Fellow of BMJ Case Reports today and you can:

- Submit as many cases as you like

- Enjoy fast sympathetic peer review and rapid publication of accepted articles

- Access all the published articles

- Re-use any of the published material for personal use and teaching without further permission

For information on Institutional Fellowships contact consortiasales@bmjgroup.com

Visit casereports.bmj.com for more articles like this and to become a Fellow 